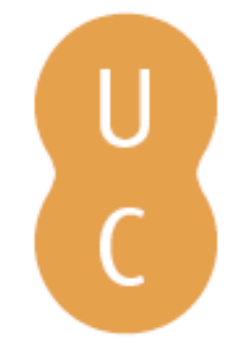

\title{
pompalina
}

\section{O sistema alimentar da cidade do Rio de Janeiro no século XVIII: as louças destinadas ao serviço e consumo de alimentos}

Autor(es): $\quad$ Peixoto, Sílvia; Lima, Tania Andrade

Publicado por: Imprensa da Universidade de Coimbra

URL

persistente: URI:http://hdl.handle.net/10316.2/45256

DOI: $\quad$ DOI:https://doi.org/10.14195/978-989-26-1720-6_16

Accessed : $\quad$ 26-Apr-2023 16:23:18

A navegação consulta e descarregamento dos títulos inseridos nas Bibliotecas Digitais UC Digitalis, UC Pombalina e UC Impactum, pressupõem a aceitação plena e sem reservas dos Termos e Condições de Uso destas Bibliotecas Digitais, disponíveis em https://digitalis.uc.pt/pt-pt/termos.

Conforme exposto nos referidos Termos e Condições de Uso, o descarregamento de títulos de acesso restrito requer uma licença válida de autorização devendo o utilizador aceder ao(s) documento(s) a partir de um endereço de IP da instituição detentora da supramencionada licença.

Ao utilizador é apenas permitido o descarregamento para uso pessoal, pelo que o emprego do(s) título(s) descarregado(s) para outro fim, designadamente comercial, carece de autorização do respetivo autor ou editor da obra.

Na medida em que todas as obras da UC Digitalis se encontram protegidas pelo Código do Direito de Autor e Direitos Conexos e demais legislação aplicável, toda a cópia, parcial ou total, deste documento, nos casos em que é legalmente admitida, deverá conter ou fazer-se acompanhar por este aviso.

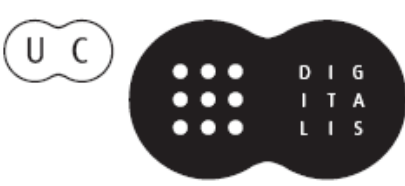


Carmen Soares

\section{Cilene da Silva Gomes Ribeiro}

\section{(coords.)}

MESAS

\section{ALIMENTAÇÃ O, SAÚDE \& CULTURA}

\section{IU LUO-BRASILEIRAS}

\section{VOLUME II}

IMPRENSA DA UNIVERSIDADE DE COIMBRA

COIMBRA UNIVERSITY PRESS

PUCPRESS 


\title{
O Sistema Alimentar da CidAde do Rio de Janeiro no século XVIII
}

\author{
(The food system in $18^{\text {th }}$ century Rio de Janeiro)
}

\author{
III. As louças destinadas ao Serviço \\ E CONSUMO DE ALIMENTOS
}

(Pottery used to serve and consume food)

\author{
Sílvia Peixoto \\ Doutoranda do Programa de Pós-Graduação \\ em Arqueologia do Museu Nacional/UFRJ \\ SILVIAPEIXOTO@GMAIL.COM
}

Tania Andrade Lima Museu Nacional/Universidade Federal do Rio de Janeiro TALIMA8@GMAIL.com

Resumo: Na área de despejo de dejetos do sítio arqueológico situado à Rua da Assembleia foi recuperada, entre os demais vestígios, grande quantidade de louças, aí compreendidas faianças e porcelanas, de diferentes procedências. Tendo em vista que nela foram descartados materiais imprestáveis das residências, estabelecimentos comerciais e instituições existentes nas imediações do terreno, essas louças pertenceram a diferentes pessoas, de origens e estratos sociais distintos, que coexistiam então no centro da cidade em expansão, constituindo uma amostra expressiva das práticas cotidianas dos seus habitantes. Neste artigo, é identificada a procedência das faianças e porcelanas resgatadas, bem como analisadas suas formas e funções, estreitamente relacionadas com o serviço e consumo dos alimentos que compunham, à época, a dieta da população. A análise indicou, a partir da constatação da predominância de pratos dentre os itens do serviço de mesa, um incipiente processo de individualização na esfera alimentar já em fins do século XVII e início do XVIII, inesperado no universo colonial a esse tempo.

PALAVRAS-CHAVE: louças, faianças portuguesas, porcelanas orientais, alimentação, Rio de Janeiro colonial.

Авstract: In the dump area at the archaeological site located at Rua da Assembleia was recovered, among other evidence, a great amount of tin-glazed earthenwares and porcelain from different origins. Given that the dump area is composed of artifacts discarded from households, commercial establishments and public institutions from the neighborhood, these ceramic types belonged to people with different origins and social positions who coexisted in the expanding downtown area of the city. 
For this reason, these artifacts are a significant sample of the daily practices of its inhabitants. In this article, we identify the origin of the tin-glazed earthenwares and porcelains found at the site and analyze their forms and functions, which were closely related to the types of food consumed at that period. The analysis indicated, given the observation of the predominance of dishes among the table service items, an incipient process of individualization in the food consumption in the late seventeenth and early eighteenth centuries, unexpected at that time.

KEYWORDs: ceramics, portuguese tin-glazed earthenwares, oriental porcelain, food comsumption, colonial Rio de Janeiro.

Em uma área de descarte coletiva no coração daquele que foi, em suas origens, o centro político, administrativo e econômico do Rio de Janeiro, espaço de grande circulação de pessoas, de diferentes origens e estratos sociais, em que coexistiam edifícios públicos, residenciais e comerciais, foi recuperada grande quantidade e variedade de faianças europeias e porcelanas orientais. Através da análise das procedências, e principalmente das formas dessas louças, pudemos vislumbrar como eram os serviços de mesa na principal área da cidade entre fins do século XVII e a primeira metade do XVIII, e como os diferentes itens que os compunham eram utilizados na esfera alimentar.

\section{i. As faianças europeias}

Foram analisados cerca de 9.000 ítens de faiança europeia e 700 de porcelana oriental, amostra que abarca tanto peças fragmentadas (que perfazem mais que $50 \%$ da peça), como fragmentos de peças (menos que 50\%), provenientes de diferentes áreas do terreno, mas sobretudo da área dos fundos, com maior concentração de materiais arqueológicos.

No que se refere às faianças europeias, trata-se de amostra que impressiona pela quantidade e diversidade de peças, provenientes em sua grande maioria de Portugal, mas também de outros centros produtores europeus, como Itália, Holanda e Espanha.

Através da análise das formas, foi possível perceber que estão presentes na amostra grande parte dos itens que integram serviços de mesa, como pratos, almofias, tigelas, malgas, jarros, potes, salseiras, covilhetes, especieiros, terrinas, de diferentes procedências e com variada decoração. Há também peças não relacionados à esfera alimentar, como caixas, salvas e mangas de farmácia. 
Não parece haver uma grande diversidade de formas produzidas em faiança durante os séculos XVI, XVII e XVIII ${ }^{1}$, como vai se observar, por exemplo, na faiança fina do século XIX. No entanto, dentro de uma mesma categoria morfológica, a variabilidade é grande, tanto no que concerne ao estilo e à decoração, como também à forma.

Associado ao conceito de forma, vem necessariamente o de função. A faiança servia principalmente à mesa, mas também figurava no âmbito da higiene pessoal e da botica. Além disso, havia ainda peças que, pela sua qualidade estética, não eram utilizadas no cotidiano, mas para fins decorati$\operatorname{vos}^{2}$. É preciso, no entanto, frisar que a multifuncionalidade inerente à louça nesse período ${ }^{3}$ impede que se atribuam funções específicas a grande parte das formas existentes à época, sendo realizada aqui apenas uma tentativa de aproximação de seu(s) uso(s) no cotidiano colonial carioca.

Para catalogação e descrição das formas encontradas na amostra, recorremos aos especialistas que há anos vêm se debruçando sobre o tema ${ }^{4}$. Deve-se, no entanto, levar em consideração a variabilidade não só das formas catalogadas por esses autores, mas, sobretudo, das nomenclaturas dadas às peças. Foi preciso, com isso, mesclar informações provenientes de diferentes trabalhos, para contemplar o material encontrado em nossa amostra.

A partir de informações oriundas de coleções museológicas, dos acervos exumados em escavações arqueológicas, bem como da documentação dos séculos XVI ao XVIII, especialmente o Regimento dos Oleiros de 1572, e tendo ainda como base a utilização que ainda hoje se dá a estas peças, reconhecemos na amostra da Assembleia as seguintes formas:

Prato - forma aberta, geralmente subtroncocônica, de paredes baixas, assente em fundo de pé anelar de menor diâmetro que a abertura. Apresenta uma grande variabilidade de diâmetros, e era destinado a ser utilizado individualmente à mesa, no consumo de alimentos.

Palangana/Prato "galinheiro" - prato de grandes dimensões, normalmente de maior espessura. Por suas dimensões não devia ser usado para consumo individual, como os demais pratos.

Almofia - peça aberta, de corpo tronco-cônico, de fundo plano com pé anelar de menor diâmetro que a abertura da peça. Gomes ${ }^{5}$ distingue três tipos distintos na formulação do bordo: Almofia de Bordo Espessado, que apresenta o bordo espessado num lábio de secção tendencialmente circular;

\footnotetext{
Casimiro 2010: 580.

Idem.

Cf. Gomes 1996; Fernandes 2003: 156-158.

Casimiro op cit.; Castro 2009; Gomes 2011.

Gomes op cit.: 117 .
} 
Almofia de Bordo Extrovertido, onde o bordo se apresenta extrovertido em relação à parede, criando uma espécie de aba, e, por último, a Almofia de Bordo Boleado, em que o bordo não apresenta nenhuma variação de inclinação.

Terrina/Sopeira - forma fechada, exibindo, normalmente, dois pegadores nas laterais, e quase sempre acompanhada por uma tampa. Destinada a servir alimentos líquidos, como sopas ou ensopados, à mesa.

Malga/Taça - forma aberta, de corpo mais hemisférico, de bordo boleado, ligeiramente extrovertido e com pé anelar tendencialmente alto. Destinada a ser utilizada de maneira individual à mesa, no consumo de alimentos.

Tigela - forma aberta, de corpo cilíndrico mediano, bordo boleado, fundo plano e pé anelar com diâmetro ligeiramente menor que a abertura da peça. Segundo alguns autores, destinada a ser utilizada individualmente à mesa, no consumo de alimentos. No entanto, as de maiores dimensões certamente eram destinadas a servi-los.

Covilhete - pequeno prato covo, por vezes também atribuído a tigela de pequenas dimensões e mais rasa, cuja principal função seria a de servir doces.

Salseira - peça aberta de pequeno diâmetro, bordo de perfil triangular, paredes oblíquas, de fundo côncavo e base circular rasa, de menor diâmetro que a abertura. Está sempre associada à faiança sem decoração, e era utilizada para servir molhos.

Especieiro - forma aberta, de pequenas dimensões, cuja função era a de levar especiarias à mesa.

Jarro - forma fechada, de corpo globular, com uma ou duas asas, destinada a conter líquidos.

Pote - forma fechada, bojuda e globular, de diferentes dimensões, destinada a conter líquidos ou sólidos no seu interior.

Caixa - forma fechada, de paredes altas, de secção triangular, quadrangular, pentagonal, lobular ou em coração, pé anelar ou vários pés circulares individuais e cujo fundo pode apresentar uma divisão central. Destinada a guardar bens no seu interior, acompanhadas quase sempre por uma tampa.

Salva/Bilheteira - forma aberta, espécie de "bandeja" destinada a conter correspondência e outros papéis.

Mangas de farmácia/Canudo de botica - forma fechada, tipo canudo, destinada a ser utilizada numa farmácia, contendo ervas e produtos medicinais.

Em uma análise quantitativa da amostra, observou-se que a predominância é dos pratos, com $55 \%$ de frequência, seguidos pelas almofias, com $31 \%$ e, em menor quantidade, tigelas e malgas, com $5 \%$ cada uma. Jarros e salseiras têm incidência bem menor, com $3 \%$ e $1 \%$, respectivamente, e os demais itens têm frequência baixíssima, praticamente irrelevante (Gráfico 1). 


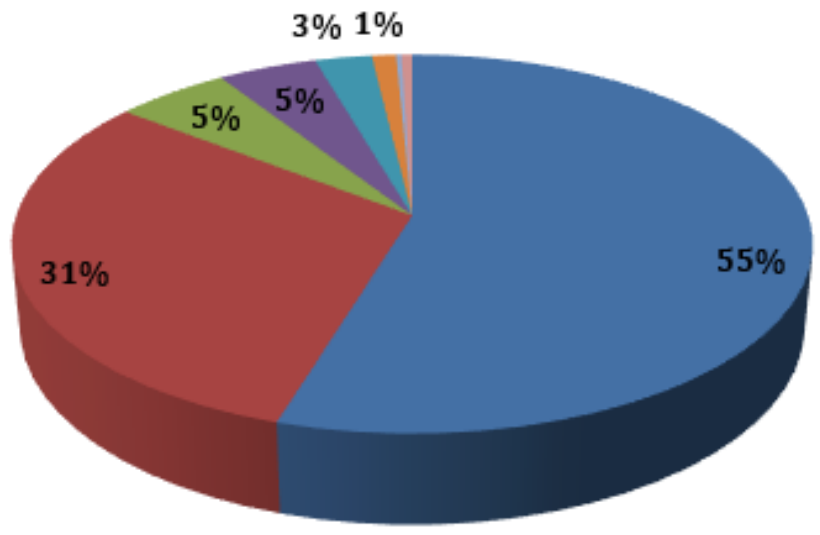

Pratos

- Almofias

Malgas

- Tigelas

- Jarros

Salseiras

Terrinas

Outros

Gráfico 1: Porcentagens das formas da faiança portuguesa

No interior das categorias mais relevantes numericamente, há grande variedade morfológica. Os pratos têm perfis diversos, porém os portugueses, de dimensões maiores, tendem a ser mais fundos (Figura 1). Os holandeses e especialmente os italianos são mais rasos e mais delicados. Dentre os portugueses há certa homogeneidade de tamanho, com exceção das chamadas palanganas, ou pratos galinheiros, pratos de grandes dimensões e muito espessos, porém sua incidência é relativamente pequena, se comparado aos de dimensões mais modestas (Figura 2).

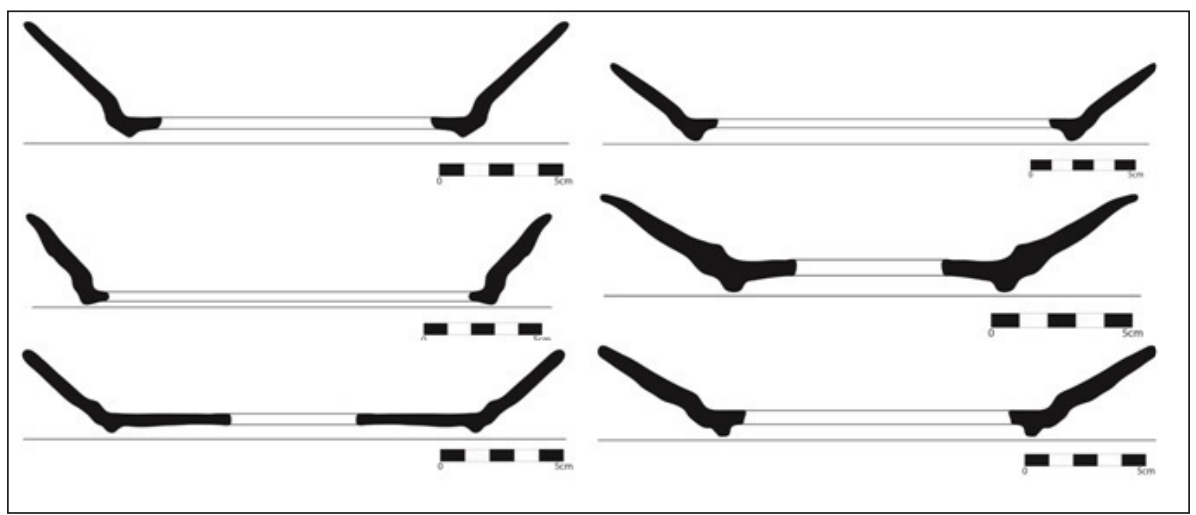

Figura 1: Perfis dos pratos portugueses

Desenho: Fernando Martins. 


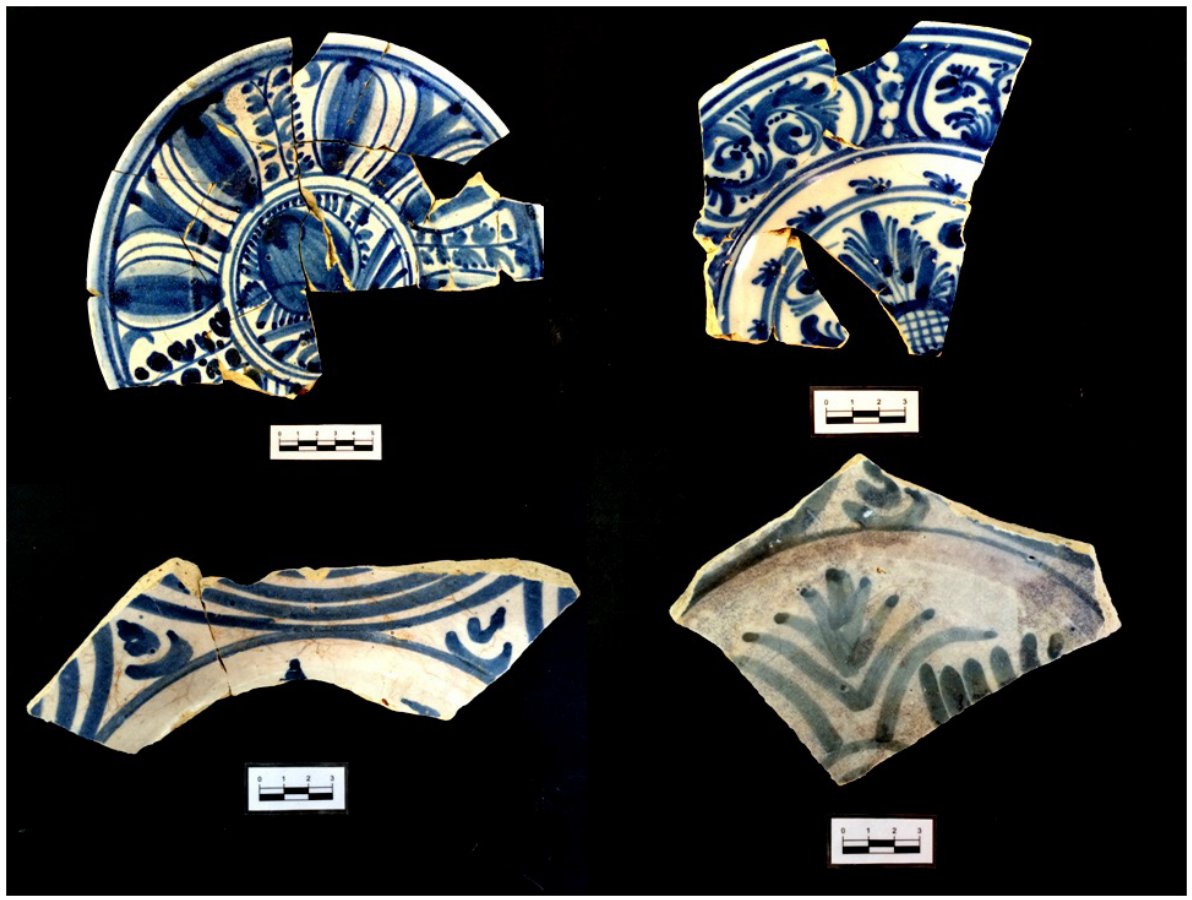

Figura 2: Pratos em faiança portuguesa - tamanho padrão (acima) e palanganas (abaixo) Foto: Sílvia Peixoto.

As almofias também variam bastante, não tanto na forma, mais homogênea, mas no tamanho, apresentando tanto vasilhas menores quanto bem grandes, essas mais recorrentes (Figura 3). O que tende a variar na forma da almofia é a inclinação da parede e o bordo, e na amostra da Assembleia a maioria das almofias possui o bordo espessado (Figura 4). 
O sistema alimentar da cidade do Rio de Janeiro no século XVIII

III. As louças destinadas ao serviço e consumo de alimentos

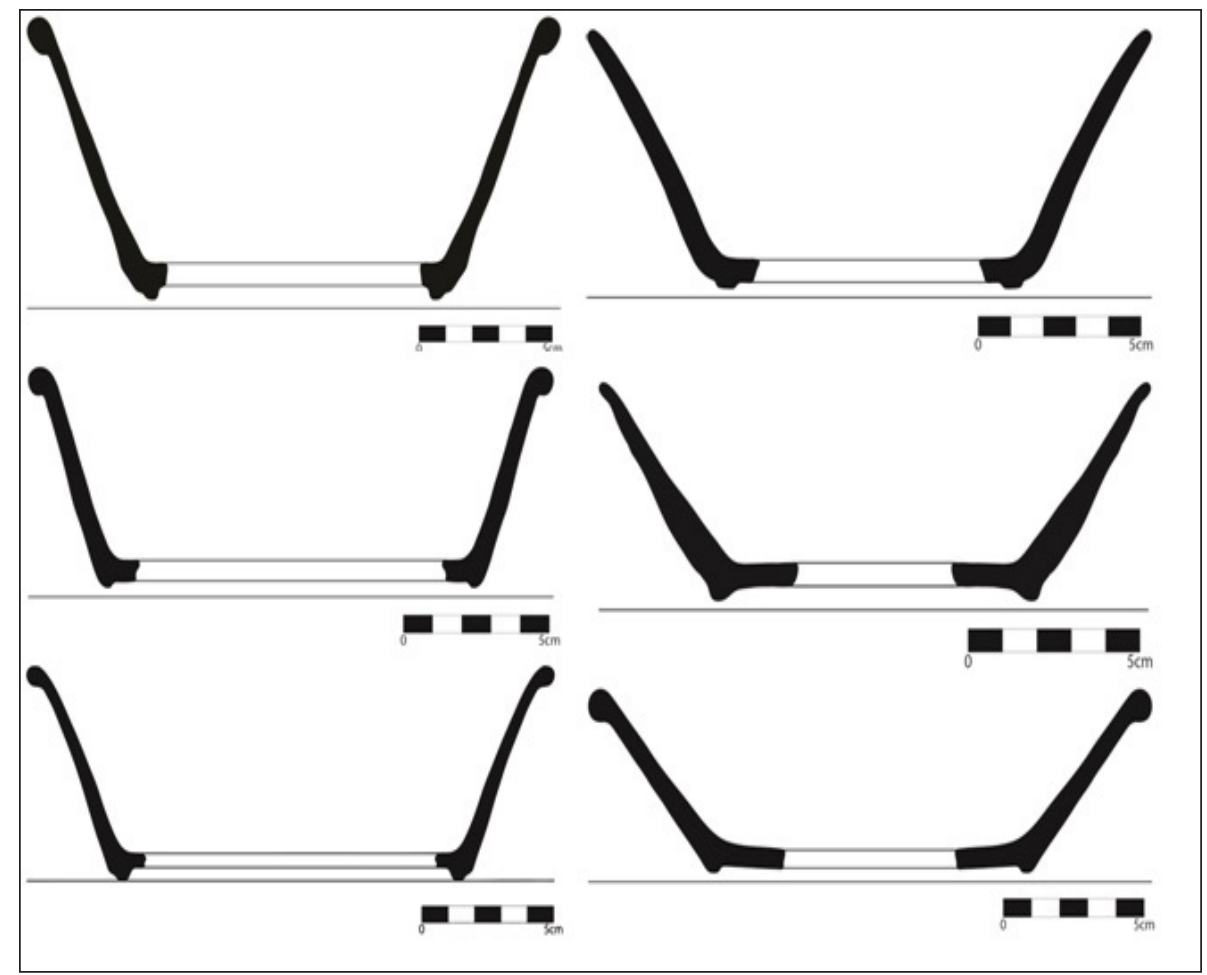

Figura 3: Perfis das almofias

Desenho: Fernando Martins. 


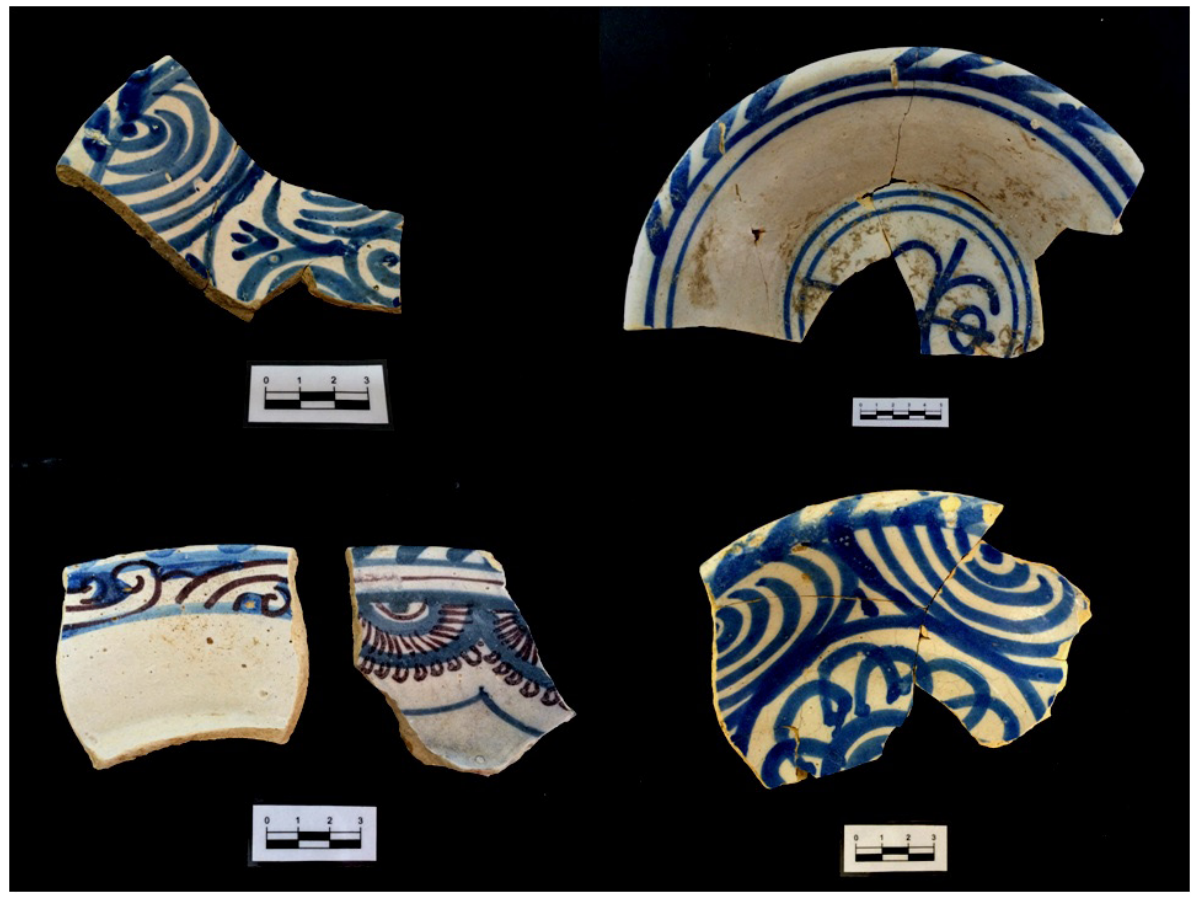

Figura 4: Almofias de bordo espessado, de diferentes dimensões Foto: Sílvia Peixoto.

As malgas e tigelas, ainda que em número bem menor que os pratos e almofias, apresentam igualmente relativa variedade no tamanho, mais do que na forma, ainda que essa também varie um pouco (Figura 5). As tigelas, especialmente, se apresentam tanto mais rasas, como com as paredes mais elevadas. Já as malgas variam mais no que se refere à forma da base, que pode se apresentar tanto plana, como com pé. Além disso, foram identificadas também algumas poucas malgas de maior espessura e dimensão (Figura 6). 


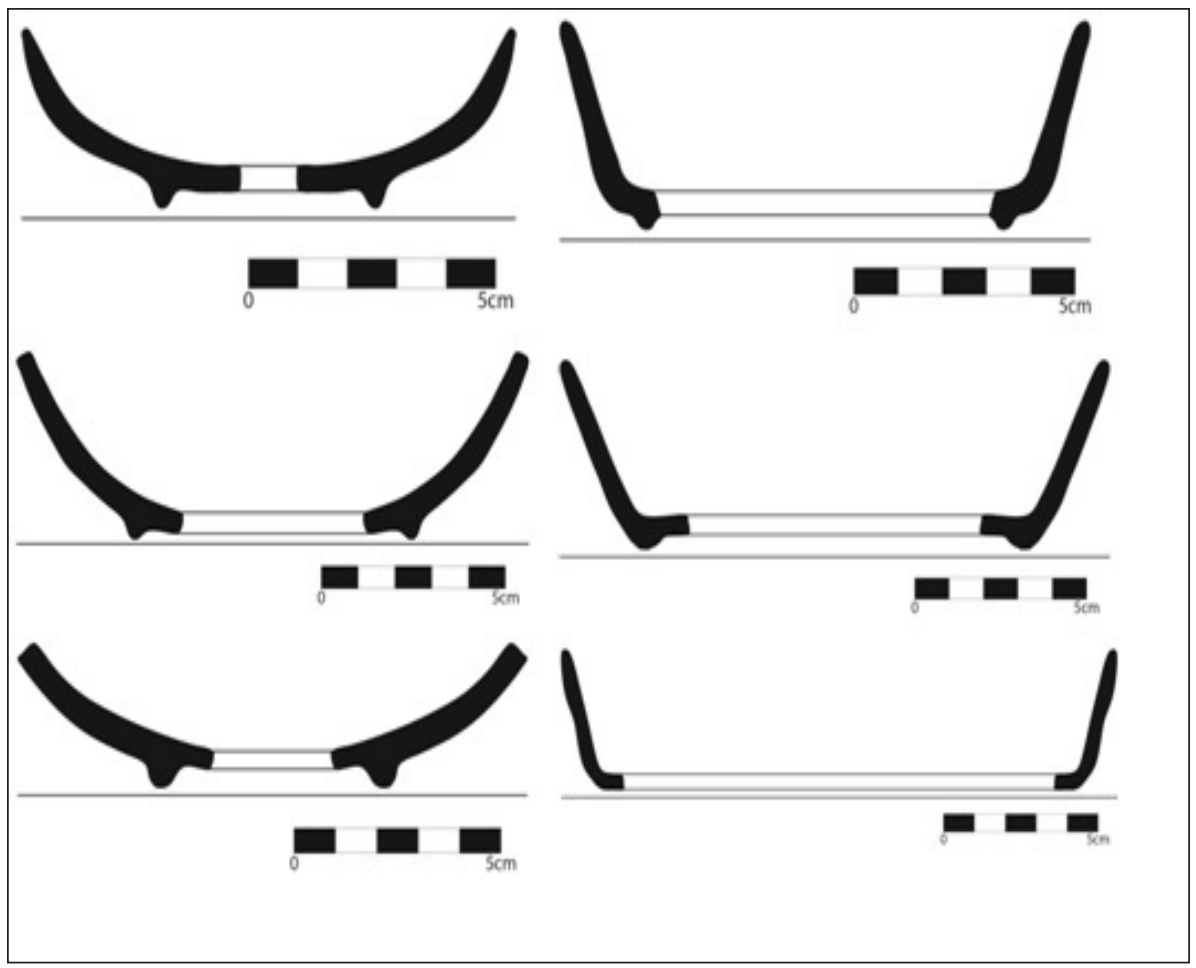

Figura 5: Perfis das malgas (esquerda) e tigelas (direita)

Desenho: Fernando Martins. 


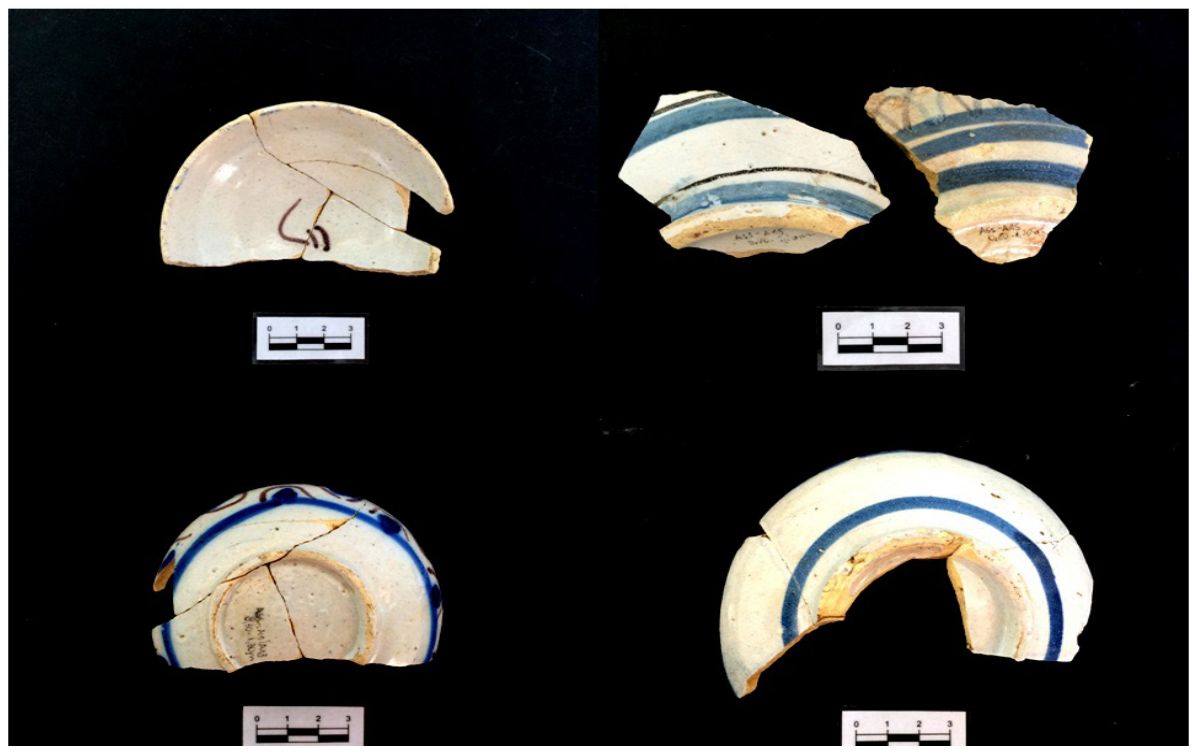

Figura 6: Malgas de diferentes dimensões Foto: Sílvia Peixoto.

Os demais itens observados - terrinas, jarros, manga de farmácia, salseiras, covilhetes e salvas - apresentam-se um pouco mais homogêneos no que se refere à forma (Figura 7).
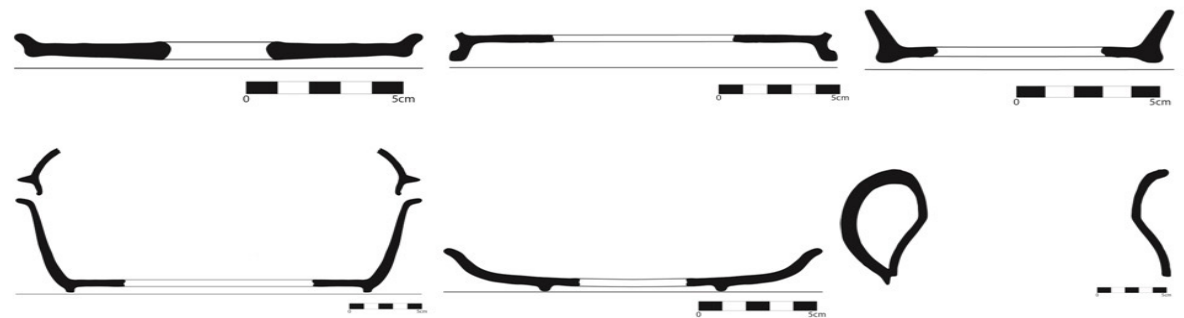

Figura 7: Perfis de peças diversas

Nota: Acima (da esquerda para a direita): salseira, salva e pote. Abaixo (da esquerda para a direita): terrina, covilhete e jarro.

Desenho: Fernando Martins. 
No que diz respeito aos motivos decorativos da faiança portuguesa, observa-se acentuada predominância de peças decoradas, em detrimento das lisas. A maior incidência é das decorações em azul e branco, tanto as mais simples, geométrico-vegetalistas, como os semicírculos concêntricos, mas há, mesmo que em menor grau, grande variedade decorativa, incluindo praticamente todas as gramáticas decorativas presentes na faiança portuguesa: desenho miúdo, rendas, contas, faixa com folhas de acanto, heráldico, aranhão, sino-português, pseudo-epigráfica, Monte Sinai, etc. (Figura 8).

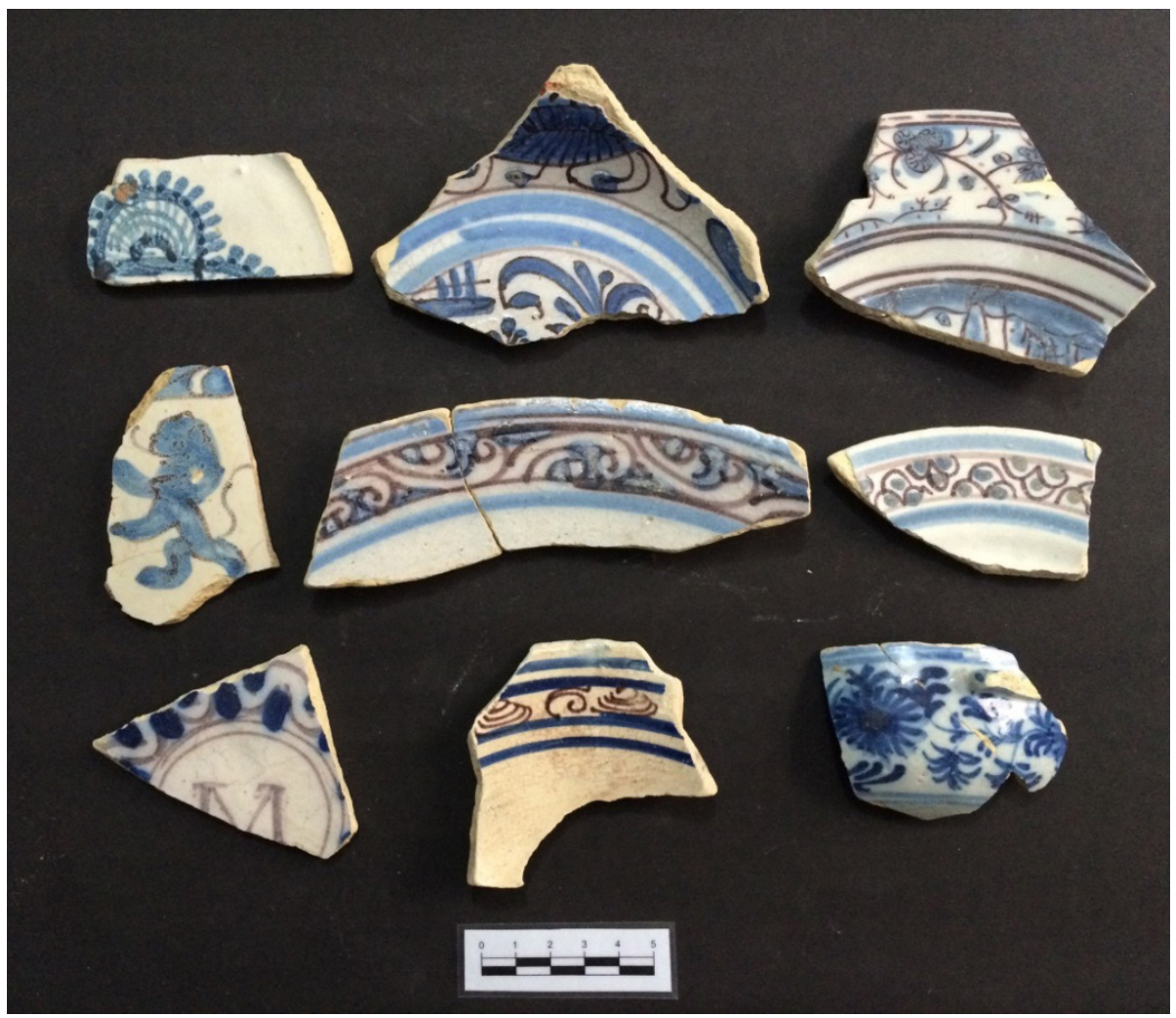

Figura 8: Decorações das faianças portuguesas com cronologias atribuídas à segunda metade do século XVII e primeiras décadas do século XVIII

Nota: Da esquerda para a direita e de cima para baixo: Rendas; Aranhão; Desenho Miúdo; Heráldico; Faixa com folhas de acanto; Contas; Faiança de encomenda (com letra); Pseudo-epigráfico e Monte Sinai.

Foto: Sílvia Peixoto. 
No que se refere às faianças europeias não portuguesas, denominadas aqui de "faianças estrangeiras", elas perfazem apenas $2 \%$ do total da amostra analisada. Dentre elas, o predomínio é de peças de fábricas da Ligúria, na Itália, com 53\% de frequência, seguido por Delft, na Holanda, com 23\%, e Espanha e Montelupo, também na Itália, com 19\% e 5\%, respectivamente.

As faianças provenientes da região da Ligúria, no Noroeste italiano, cujos principais centros produtores são Gênova e Albíssola, se caracterizam pelo uso de esmalte "berettino" e pintura designada de "azul sobre azul", que utiliza tons de azul mais escuro sobre azul mais claro. As de Delft, na Holanda, da mesma maneira, apresentam características muito próprias, com a utilização de um esmalte muito brilhante e pintura em vários tons de azul, dos mais escuros aos mais claros. Na segunda metade do século XVII emprega-se, igualmente, o manganês ou o preto para o contorno do desenho, sendo grande parte dos motivos de influência oriental ${ }^{6}$.Já as faianças de Montelupo, na região da Toscana, Itália, se caracterizam pela intensa policromia, variando em composições de azul e vermelho, azul e laranja ou azul, verde, amarelo e marrom (Figura 9).

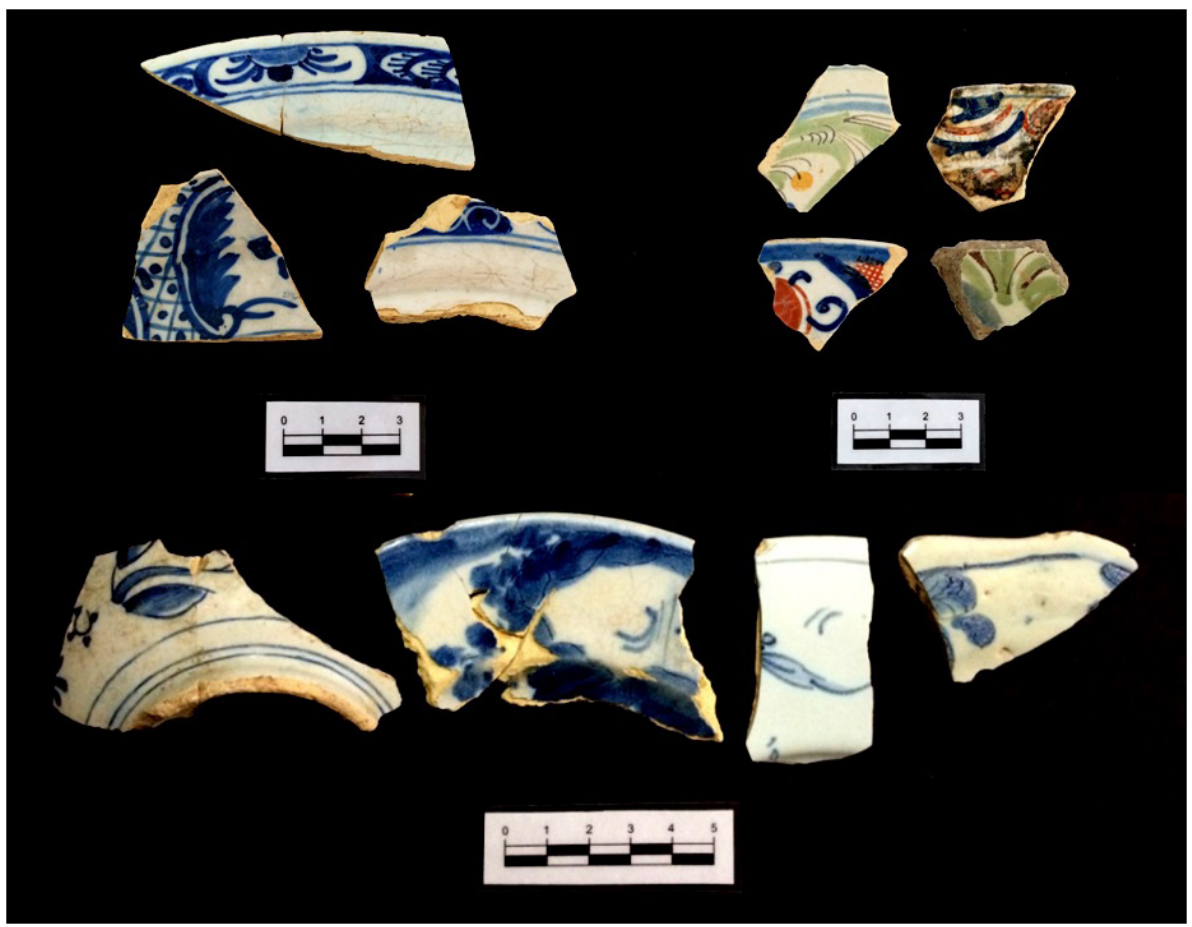

Figura 9: Faianças holandesas e italianas, produções de Delft (acima à esquerda), Montelupo (acima à direita) e Ligúria (abaixo)

Foto: Sílvia Peixoto.

$6 \quad$ Castro op cit.: 149. 
As faianças holandesas apresentam-se majoritariamente sob a forma de pratos, que perfazem $47 \%$ da amostra, e em menor incidência potes, com $6 \%$, e malgas e tigelas, com $3 \%$ de frequência cada. As italianas, da Ligúria, tem o predomínio dos pratos, rasos e de fina espessura (26\% para Ligúria e $29 \%$ para Montelupo), seguidos pelas malgas, com 11\%. Já as faianças espanholas se apresentam principalmente sob a forma de almofias (de bordo extrovertido), com 44\%, e pratos, com 37\% (Gráfico 2).

\section{Delft}

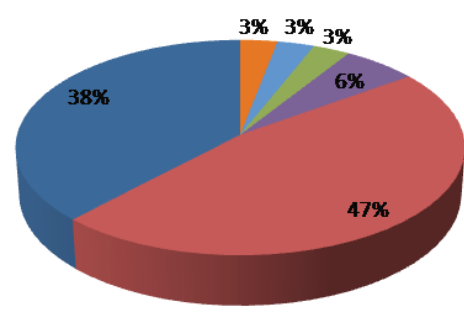

Espanha

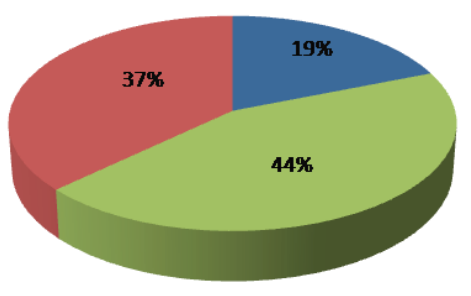

Ligúria

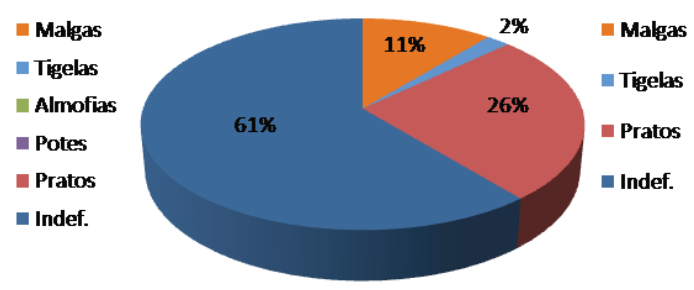

Montelupo
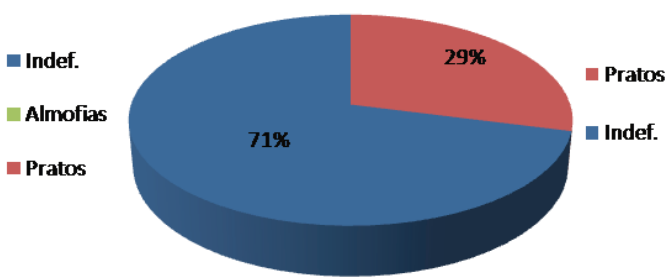

Gráfico 2: Porcentagens das formas em faianças holandesas, espanholas e italianas

Em termos quantitativos, não é de todo inesperado que os pratos tenham predominado na amostra, tendo em vista o caráter individual desse item no serviço de mesa. Cabe mencionar que o mesmo predomínio foi verificado por Gomes ${ }^{7}$ em análise das faianças resgatadas da Praça da Sé, em Salvador. Contudo, surpreende esse processo de individualização em um recorte temporal tão recuado, no qual as malgas e tigelas usualmente tendem a prevalecer na esfera alimentar. A esse respeito, cabe uma análise comparativa com o contexto 
colonial americano, analisado pelo arqueólogo James Deetz ${ }^{8}$. O pesquisador observa, para o período que vai de 1660 a 1760, uma escassez de pratos nas coleções arqueológicas, e atribui a grande parte deles um uso não funcional, que chama de sociotécnico, no qual os pratos transitavam mais no âmbito cerimonial do que no propriamente alimentar. Deetz observa que o aumento dramático na quantidade de pratos só ocorreu a partir de aproximadamente 1760, mudança que refletiu um novo arranjo entre os indivíduos e a cultura material, com a substituição do compartilhamento de objetos pelo uso individualizado deles. Para o arqueólogo, trata-se da expressão da visão de mundo georgiana, emergente à época, caracterizada pela ordem, pelo controle, pelo equilíbrio e pela crescente importância do indivíduo: " $A$ one person/one dish relationship is symmetrical, while a number of people sharing a single dish, or a single chamber pot, is definitely not" ${ }^{\text {. }}$

É interessante observar, portanto, que a amostra analisada por nós, de intervalo cronológico análogo ao período em que Deetz atribui a escassez de pratos nos contextos arqueológicos americanos, se apresenta de maneira diferente, com a predominância precisamente desses itens no serviço de mesa, mesmo para os períodos inseridos ainda no século XVII. Ao que tudo indica, o uso individual dos pratos no consumo de alimentos já era regra no Rio de Janeiro colonial a partir dos Seiscentos, ao menos para as residências do centro político-administrativo da cidade ${ }^{10}$.

No que diz respeito às almofias, essas são peças normalmente multifuncionais, utilizadas tanto para o armazenamento na cozinha, como para servir à mesa diferentes tipos de alimentos, de frutas a caldos. Não surpreende, portanto, sua alta incidência na amostra, ficando atrás apenas dos pratos, tendo em vista os diferentes usos que se podia dar a esse tipo de recipiente.

As malgas, ainda que sejam, como os pratos, peças de uso individual, normalmente destinadas ao consumo de caldos, se mostraram, como já mencionado, itens acessórios no serviço de mesa analisado. A exceção parece se dar com as malgas de maior dimensão, com pé, que podem ter sido utilizadas para servir caldos e afins na mesa. $\mathrm{O}$ mesmo parece ocorrer com as tigelas, de mesma incidência na amostra, que podem ter sido utilizadas tanto no serviço como no consumo de alimentos, tendo em vista a variabilidade observada nas dimensões das peças e na altura das paredes. Ainda que sejam atribuídas por alguns autores ao uso individual ${ }^{11}$, como já dito, há tigelas que, por suas dimensões, sugerem ter sido destinadas a servir os alimentos à mesa.

\footnotetext{
8 Deetz 1996: 83-86.

Idem: 86.

10 A exceção parece ter se dado com os grandes pratos designados como galinheiros, ou palanganas, possivelmente itens de uso coletivo, associados ao serviço de alimentos à mesa.

11 Casimiro op cit.: 585.
} 
Infelizmente, a categoria jarro/vaso não é muito diagnóstica ou informativa no que se refere ao uso, pois a forma desses dois recipientes é bastante semelhante, às vezes diferenciando-se por apenas uma alça, porém sua utilização pode ter sido bastante variada.

As salseiras, ainda que sejam itens acessórios/de apoio no serviço de mesa, têm uma representatividade razoável na amostra, se comparadas a outras peças, como os covilhetes, por exemplo, bastante raros. Destinadas a conter molhos e condimentos com que se "adubava a comida", as salseiras são tidas por alguns autores como itens de uso individual, ainda que sua incidência na amostra não indique isso.

É interessante observar que as terrinas/sopeiras são raras no material da Assembleia. No entanto, deve-se levar em consideração que somente a partir de meados do século XVIII é que elas passam a ser a peça principal dos serviços de mesa ${ }^{12}$. Até esse momento, as almofias, ou mesmo as tigelas maiores, certamente desempenharam a função de servir alimentos líquidos. Essa baixa incidência das sopeiras é compatível com a cronologia atribuída à área de descarte, de final do século XVII a meados do século XVIII.

Os demais itens identificados, de ínfima incidência na amostra, normalmente tinham funções muito específicas, caso dos especieiros, e por vezes fora do âmbito do serviço de mesa, como as mangas de farmácia, caixa e salvas/bilheteiras.

\section{As PORCELANAS ORIENTAis}

Compõem a amostra de porcelanas orientais, resgatadas na Rua da Assembleia, 718 ítens, dentre fragmentos de peças e peças fragmentadas, de diferentes decorações e cronologias de produção.

A análise das porcelanas orientais indicou um padrão distinto do verificado para as faianças. Em primeiro lugar, não se observa a variedade de formas que há nas faianças europeias, porém há variações que não existem nas outras, como malgas muito pequenas e grandes tigelas, que se assemelhariam mais, em termos funcionais, às almofias verificadas na faiança.

Basicamente, o que se observou das formas na porcelana são malgas, tigelas e pratos. A predominância absoluta é das malgas, com 68\%, seguida pelos pratos, com $19 \%$, e tigelas, que perfazem $13 \%$.

No que concerne aos motivos decorativos, e, consequentemente, à cronologia, a amostra apresentou porcelanas de três períodos: produções associadas ao reinado do imperador Wanli, sendo mais expressiva a presença

\footnotetext{
12 Domingues 2006: 186.
} 
das produções de início do século XVII, designadas como porcelana Kraak; já enquadrável no último quartel do século XVII as produções da província de Zhangzhou, também denominadas porcelana Swatow, caracterizada pelo traço grosso da decoração, em azul escuro, e pasta acinzentada; e, por último, as produções polícromas dos reinados de Kangxi (1661-1722) e Yongzheng (1723-1735), denotando-se o uso da cor vermelha, das decorações florais e do castanho para a cobertura dos exteriores das peças (Figura 10).

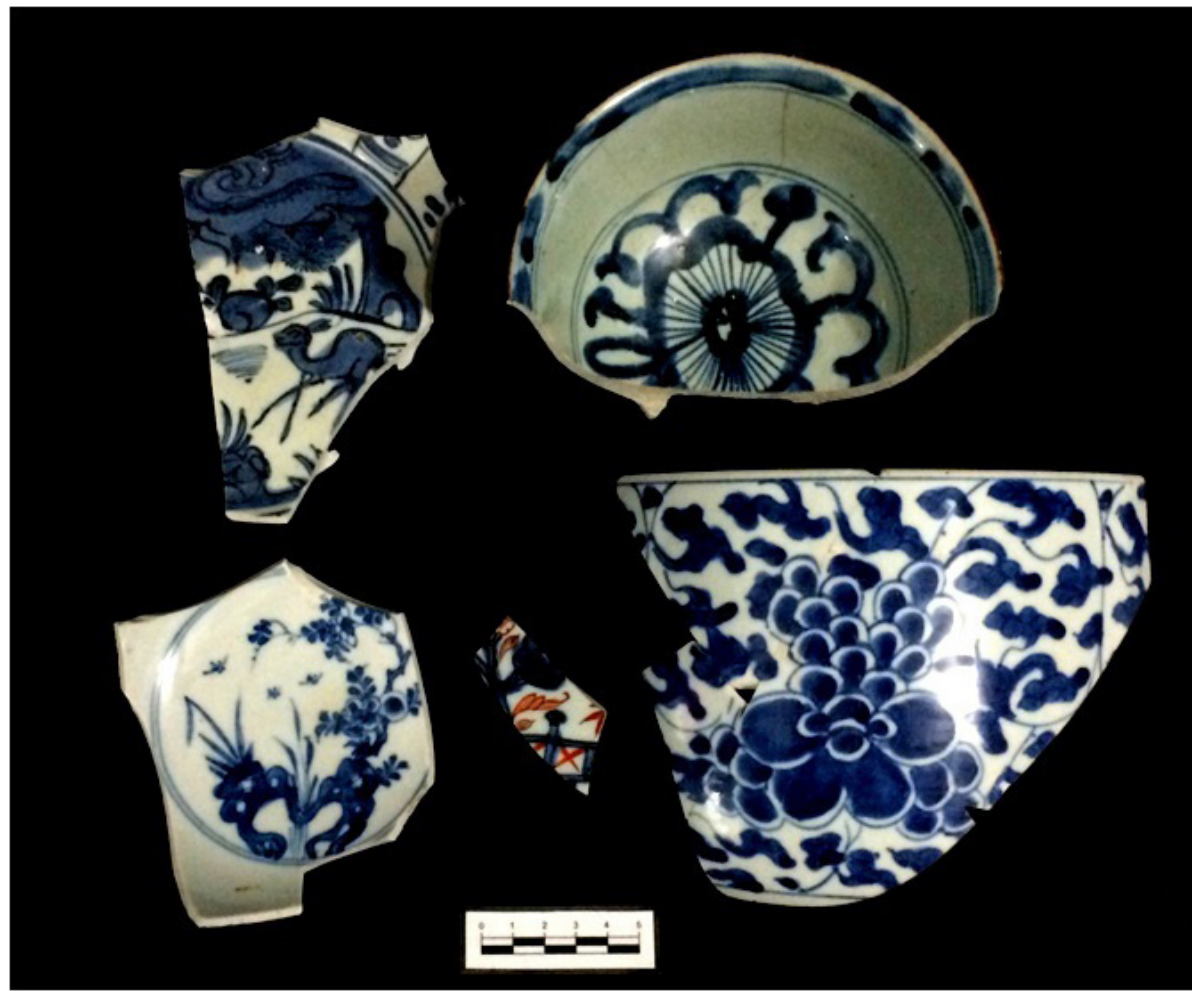

Figura 10: Porcelanas chinesas. Da esquerda para a direita e de cima para baixo: tipo Kraak, tipo Swatow e três exemplares dos reinados Kangxi-Yongzheng (1654-1735), incluindo uma grande tigela, à direita

Foto: Sílvia Peixoto.

Ainda que o conjunto de porcelanas apresente peças desses três períodos, é preciso, no entanto, salientar que as porcelanas Kraak, mais recuadas cronologicamente, tem baixíssima frequência na amostra, sendo a maior porcentagem a de peças Swatow, seguida pelas da Dinastia Kangxi, configurando, portanto, um intervalo que vai de fins do século XVII à primeira metade do XVIII, confirmando o que as faianças já haviam apontado. 
Tendo em vista o alto valor de mercado da porcelana oriental, era esperado que sua incidência na amostra de louças da Assembleia fosse bem menor que a da faiança. Esse itens eram certamente exclusivos dos segmentos mais abastados, ou, se não exclusivos, figuravam nas mesas dos menos aquinhoados apenas em ocasiões especiais, dificilmente fazendo parte do seu cotidiano.

\section{Considerações finais}

Em se tratando de uma colônia de Portugal, é surpreendente a quantidade de pratos encontrada em uma amostra atribuída ao final do século XVII e primeira metade do XVIII. Como relata Norbert Elias ${ }^{13}$, inexistiam no século XVI peças individuais e a comida sólida era colocada sobre grandes rodelas de pão, à guisa de suportes. As sopas ficavam em caldeirões, igualmente coletivos, e eram ingeridas em conchas. Os pratos individuais surgiram apenas no século XVII, a princípio de madeira ou de metais, como estanho, posteriormente em louças, porém restritos às classes dominantes. A sua inesperada frequência no registro arqueológico da Rua da Assembleia, ao final desse mesmo século, atesta uma prática já bem consolidada entre a população do Rio de Janeiro, configurando uma rápida disseminação, na colônia, dos novos comportamentos que emergiam então nos grandes centros europeus.

Esse número elevado de pratos, majoritariamente de faiança portuguesa, e, em menor escala, italiana, holandesa e espanhola, permite entrever a relação das suas formas com os hábitos alimentares à época. Na produção de faianças em Portugal, chama a atenção a fundura dos seus pratos, se comparada à dos demais que foram recuperados, produzidos em outros países, bem mais rasos (Figura 11).

\footnotetext{
13 Elias 1990.
} 


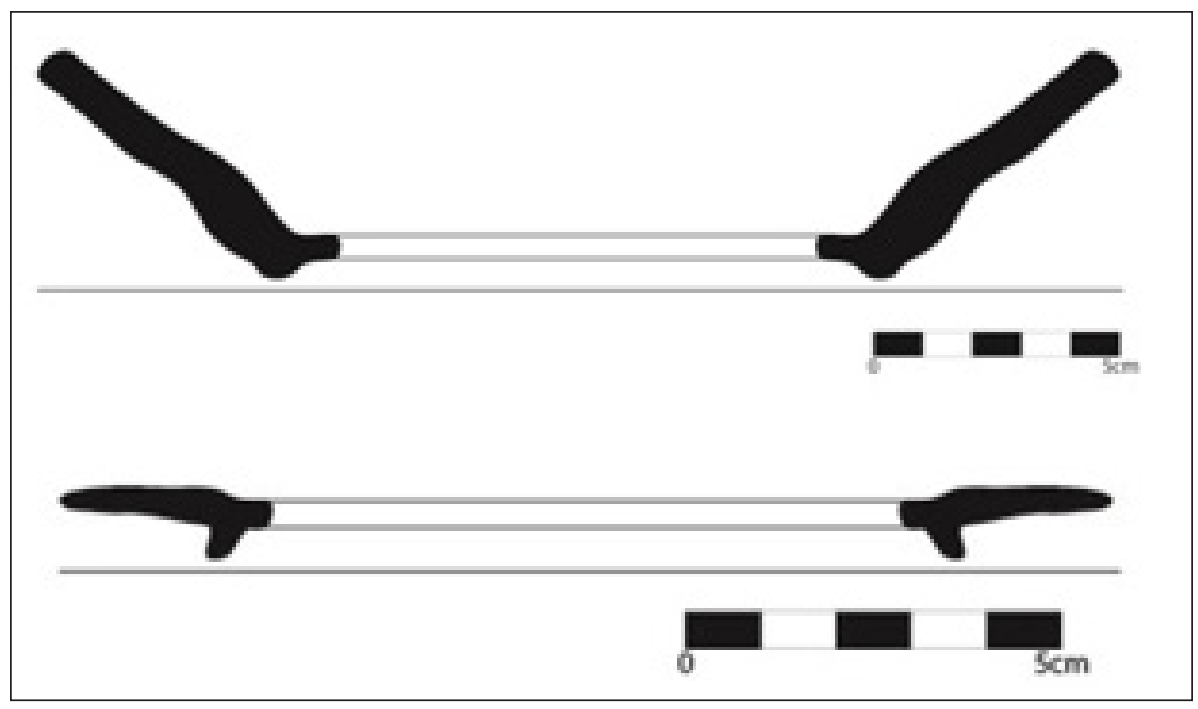

Figura 11: Diferenças de profundidade entre os pratos em faiança portuguesa (acima) e italiana (abaixo)

Desenho: Fernando Martins.

Como as manufaturas desenvolviam sua produção de acordo com os interesses dos consumidores, fica evidente a opção preferencial dos portugueses pelas formas covas, o que por sua vez tem forte correlação com sua dieta alimentar. É inequívoca a sua associação com as sopas, caldos, cozidos, ensopados, guisados, molhos, etc., abundantes na rica culinária portuguesa, como bem demonstram os livros de receitas Arte de Cozinha, de autoria de Domingos Rodrigues, publicado em 1621, e Cozinheiro Moderno, de Lucas Rigaud, publicado em 1780. Em contrapartida, deviam ser predominantes os alimentos mais consistentes na culinária dos demais países (Holanda, Itália, Espanha), a julgar pela pouca profundidade dos seus pratos.

Essa amplitude de variação - tanto qualitativa quanto quantitativa - corrobora a interpretação da área de despejo de lixo como altamente representativa dos diferentes segmentos sociais estabelecidos na zona central do Rio de Janeiro à essa época: desde os mais elevados, a quem estão sendo atribuídas as porcelanas orientais, as faianças "estrangeiras" e as de Portugal, até o das pessoas livres, comuns e sem distinção, que tinham também em suas casas as abundantes faianças portuguesas que foram recuperadas na pesquisa. $\mathrm{E}$ que, acompanhando os novos comportamentos que surgiam, rapidamente, estavam deixando para trás o hábito de comer em pratos coletivos, em favor do ainda incipiente processo de individualização, que viria a eclodir em toda a sua plenitude nos séculos posteriores. 


\section{Agradecimento}

Agradecemos a João Pedro Gomes, pelo inestimável auxílio na identificação de algumas formas e decorações das faianças e porcelanas aqui apresentadas.

\section{REFERENCIAS}

Casimiro, T. (2010), Faiança portuguesa nas Ilhas Britânicas: dos finais do século XVI aos inícios do século XVIII, Tese de Doutorado em História, Faculdade de Ciências Sociais e Humanas, Universidade Nova de Lisboa, Lisboa.

Castro, A. S. (2009), Cerâmica europeia de importação no Mosteiro de S. João de Tarouca (séculos $X V$-XIX), Dissertação de Mestrado em História e Arqueologia da Expansão Portuguesa, Faculdade de Ciências Sociais e Humanas, Universidade Nova de Lisboa, Lisboa.

Deetz, J. (1996), In small things forgotten: an archaeology of early American life, Anchor Books, New York.

Domingues, C. M. (2006), Dicionário de cerâmica, Edição Caleidoscópio, Portugal.

Elias, N. (1990), O processo civilizador: uma história dos costumes, Jorge Zahar, Rio de Janeiro.

Gomes, J. P. (2011), Faiança portuguesa na capital do Brasil Seiscentista, Dissertação de Mestrado em História da Arte, Faculdade de Letras, Universidade de Coimbra, Coimbra.

Gomes, P. D. (1996), "O livro de cozinha da Infanta D. Maria", Olaria 1: 93-104.

Fernandes, I. M. (2003), "Vasilhas: em barro se fazem, de barro se usam - o quotidiano visto através da olaria”, in R. H. Silva, I. M. Fernandes, R. B. Silva (eds.), Olaria portuguesa: do fazer ao usar, Assírio \& Alvim, Lisboa, 61-67. 
(Página deixada propositadamente em branco) 